\title{
Analysis of steel reinforced functionally graded concrete beam cross sections
}

\author{
Shota Kiryu ${ }^{1}$, Ay Lie $\mathrm{Han}^{2}$, Ilham Nurhuda ${ }^{3}$, and Buntara S. Gan ${ }^{4, *}$ \\ ${ }^{1}$ Department of Architecture, Graduate School of Engineering, Nihon University, Koriyama, Japan \\ ${ }^{2}$ Structural and Material Laboratory, Diponegoro University, Tembalang, Semarang, Indonesia \\ ${ }^{3}$ Civil Engineering Departement, Diponegoro University, Tembalang, Semarang, Indonesia \\ ${ }^{4}$ Department of Architecture, College of Engineering, Nihon University, Koriyama, Japan
}

\begin{abstract}
Owing to continuously changing strength moduli properties, functionally graded concrete (FGC) has remarkable advantages over the traditional homogeneous concrete materials regarding cement optimization. Some researchers have studied mechanical behaviors and production methodologies. Problems arise as to how to incorporate the effects of the non-homogeneity of concrete strengths in the analysis for design. For a steel Reinforced Functionally Graded Concrete (RFGC) beam structure, the associated boundary conditions at both ends have to be at the neutral axis position after the occurrence of the presumed cracks. Because the neutral axis is no longer at the mid-plane of the beam crosssection, an iterative procedure has to be implemented. The procedure is somewhat complicated since the strength of the beam cross section has to be integrated due to the non-homogeneity in concrete strengths. This paper proposes an analytical procedure that is very straightforward and simple in concept, but accurate in designing the steel reinforced functionally graded concrete beam cross-sections.
\end{abstract}

\section{Introduction}

Most human-made materials such as concrete and ceramics are deliberately designed and manufactured with homogeneous properties. The homogeneity is effective to ensure the safety of a structure. However, sometimes it can lead to ineffectiveness in the use of natural resources since high-stress concentration problems only occur in certain parts of the structural element. On the contrary to the homogeneity assumed in the analyses and design, steel Reinforced Concrete (RC) structure elements in built structures are mostly found as graded concrete material [1-2]. The non-homogeneous material property is inherent as a result of mixing, placing, consolidating and curing procedures, in addition to the segregation and accumulation of the aggregates during the mixing. Additionally, some workability factors such as bleeding and microcracking due to premature water evaporation also play a role in making the concrete material non-homogeneous.

Functionally Graded Material (FGM) is a new kind of combining two or more materials where the essential properties are varied over a specified orientation to obtain some desired

* Corresponding author: buntara@arch.ce.nihon-u.ac.jp 
function abilities [3]. In FGM compositions, two or more material properties are blended functionally to improve material performances. Bamboo is a kind of material in nature that shows a radial gradient of property as a result of the evolutionary process to adapt their living environmental conditions [4-6].

Studies on the FGC, however, are very limited. Attempts to manufacture [7-8] an FGC material face one challenging difficulty: creating a smooth transition between two different properties. Unless the continuous transition is not achieved, a laminated or composited material will be produced. The transition zones, where the stress concentrations occur, will degrade the quality of the FGC material. In [7-8], a variation in the cement content relative to volume is adapted to manufacture the FGC. The method developed in [7-8] was found useful in creating a graded material of FGC having both strength and stiffness properties varying through the depth of the concrete specimen.

Experimentally and numerically [8-11], some studies on the effects of two concrete strengths gradation of FGC cylinder compressive strength specimens have reported that the ultimate strengths of the FGC were limited by the lowest concrete strength of the FGC and their rigidities are close to the highest compressive strength of the FGC mixture.

However, FGC has not been implemented widely in construction projects. One major problem in implementing FGC is that there are no building codes available for analyzing and designing FGC elements in structures. The variation of concretes with different strengths and elastic moduli on an FGC element need an accurate method to estimate their strength and behavior. In this paper, we show a method and corresponding analysis to design a steel Reinforced Functionally Graded Concrete (RFGC) beam subjected to a bending moment. By using the presented method, the RFGC can be designed similarly with the conventional steel RC member. In the end, a study on price comparison is conducted to highlight the economic feasibility of the RFGC.

\section{Functionally graded concrete}

\subsection{FGM concept applied to the steel reinforced concrete beam}

Applying the FGM concept to the RC beam can be achieved by manufacturing the FGC reinforced by steel bars. Figure 1 depicts the resulting RFGC beam. By grading two different types of the concrete strengths throughout the thickness of the cross-section of a beam, a possible scheme to reduce the unnecessary concrete strength in the tension zone and to increase the necessary concrete strength in the compressive zone. Optimally, there will be no reduction of the beam's bending strength, and at the same time, this can potentially reduce the material prices. Similar ideas could lead to the enhancement of a wide range of other building components.

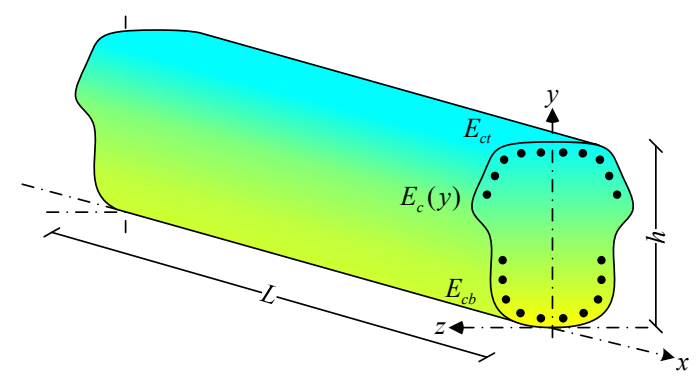

Fig. 1. RFGC beam element. 
The graded elastic modulus of the concrete beam shown in Fig. 1. and is defined by the following:

$$
E_{c}(y)=E_{c b}\left[1+\frac{E_{c t}-E_{c b}}{E_{c b}}\left(\frac{y}{h}\right)^{p}\right]
$$

where $E_{c}(y)$ is the concrete elastic modulus at $y$ ordinate; $E_{c b}$ is the concrete elastic modulus at the bottom of the beam cross-section; $E_{c t}$ is the concrete elastic modulus at the top of the beam cross-section; $y$ is measured from the bottom of the beam cross-section; $h$ is the height of the beam cross-section; and $p$ is the gradient of the modulus variation.

\subsection{Allowable stress design method of RFGC}

The allowable stress design (ASD) code standard for designing an RC beam subjected to bending moment has been used for many years. For comparison purposes in this paper, we will examine how RFGC is analyzed in the ASD and then discuss the advantages of the RFGC in the design of an RFGC beam subjected to a bending moment.

In the ASD, the following assumptions are made:

1. In the calculation of stresses at the FGC and steel bars at a section, the tensile strength of the assumed cracked concrete part below the natural axis is neglected.

2. The dimension of the length of the beam is relatively long compared to the maximum dimension of the cross-section. Hence, the section remains plane and perpendicular to the neutral axis of the beam after the deformation.

3. The material properties of steel and concrete are linear elastic.

The kinematics of the RGFC beam cross-section under a bending moment are illustrated in Fig. 2. The compression forces consist of the uncracked concrete area and steel bar in compression, while the tensile force is only resisted by the steel bar in the cracked concrete area. The design of the beam cross-section is iterated by the calculation of balancing moment strengths controlled by the concrete and steel.

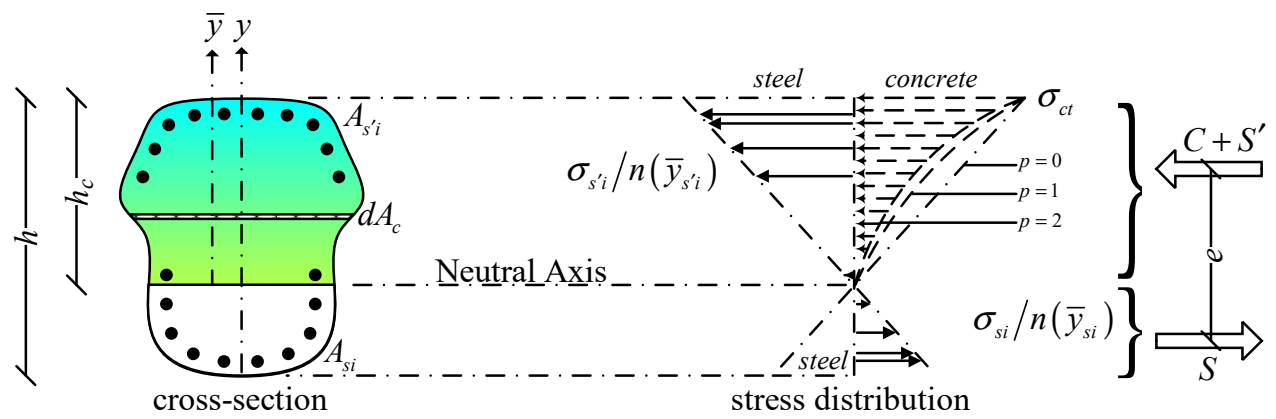

Fig. 2. Stress distribution of the cracked RFGC cross-section.

In ASD, the modular ratio, $n$, as the function of $y$ is defined as:

$$
n(y)=\frac{E_{s}}{E_{c}(y)}
$$


The equilibrium state of the steel and concrete forces after neglecting the tension portion of concrete can be obtained from the stress distributions shown in Fig. 2, which can be expressed by the following:

$$
S=C+S^{\prime}
$$

with

$$
\begin{aligned}
& S=\frac{\sigma_{c t}}{h_{c}} \sum_{i=1}^{n s} n\left(\bar{y}_{s i}\right) \bar{y}_{s i} A_{s i} \\
& S^{\prime}=\frac{\sigma_{c t}}{h_{c}} \sum_{i=1}^{n s^{\prime}} n\left(\bar{y}_{s^{\prime} i}\right) \bar{y}_{s^{\prime} i} A_{s^{\prime} i} \\
& C=\frac{\sigma_{c t}}{h_{c}} \int_{A_{c}} \bar{y} d A_{c}
\end{aligned}
$$

where $S$ is the total tensile force from the steel bars; $S^{\prime}$ is the total compressive force from the steel bars; $C$ is the total compressive force from the uncracked concrete portion; $\bar{y}, \bar{y}_{s}$ and $\bar{y}_{s^{\prime}}$ are measured from the neutral axis of the cracked beam cross section; $\sigma_{c t}$ is the stress of the concrete fiber at the top of the beam's cross-section; $h_{c}$ is the height of the uncracked steel reinforced FGC section from the neutral axis; $n s, n s^{\prime}$ are the number of tensile and compressive steel bars; and $A_{c}, A_{s i}$ and $A_{s^{\prime} i}$ are the area of the uncracked concrete, and $i$-th tensile steel bar and compressive steel bar, respectively.

By substituting Eqs. (4-6) into Eq. (3), the neutral axis position $\left(h-y_{c}\right)$ of the cracked beam cross-section can be calculated from:

$$
\int_{A_{c}} \bar{y} d A_{c}+\sum_{i=1}^{n s^{\prime}} n\left(\bar{y}_{s^{\prime} i}\right) \bar{y}_{s^{\prime} i} A_{s^{\prime} i}-\sum_{i=1}^{n s} n\left(\bar{y}_{s i}\right) \bar{y}_{s i} A_{s i}=0
$$

The second moment of inertia of the beam cross-section then can be computed by:

$$
I=\int_{0}^{y_{c}} \bar{y}^{2} d A_{c}+\sum_{i=1}^{n s^{\prime}} n\left(\bar{y}_{s^{\prime} i}\right) \bar{y}_{s^{\prime} i}^{2} A_{s^{\prime} i}-\sum_{i=1}^{n s} n\left(\bar{y}_{s i}\right) \bar{y}_{s i}^{2} A_{s i}=0
$$

The stress of an arbitrary point can be calculated by:

$$
\begin{aligned}
& \sigma_{c t}=\frac{M h_{c}}{I} \\
& \sigma_{s i}=n\left(\bar{y}_{s i}\right) \frac{\sigma_{c t} \bar{y}_{s i}}{h_{c}} \\
& \sigma_{s^{\prime} i}=n\left(\bar{y}_{s^{\prime} i}\right) \frac{\sigma_{c t} \bar{y}_{s^{\prime} i}}{h_{c}}
\end{aligned}
$$

The arm length $e$ of the couple between compressive and tensile forces of the beam cross-section can be determined from: 


$$
e=\frac{I}{\int_{A_{c}} \bar{y} d A_{c}+\sum_{i=1}^{n s^{\prime}} n\left(\bar{y}_{s^{\prime}}\right) \bar{y}_{s^{\prime} i} A_{s^{\prime} i}}=\frac{I}{\sum_{i=1}^{n s} n\left(\bar{y}_{s i}\right) \bar{y}_{s i} A_{s i}}
$$

Given the allowable stress of steel bar and concrete (compressive side), the bendingresistant moments of the RFGC beam cross-section can be determined from the lowest value between:

$$
\begin{aligned}
M_{s r} & =\frac{\bar{\sigma}_{s} I}{n\left(\bar{y}_{s b}\right) \bar{y}_{s b}} \\
M_{c r} & =\frac{\bar{\sigma}_{c} I}{h_{c}}
\end{aligned}
$$

where $M_{s r}$ and $M_{c r}$ are the allowable resisting moments of steel and concrete, respectively.

\section{Economic considerations: a price material comparison study}

In this study, the Japanese design standard for structural calculation of RC structures [12] is referred in the calculations of design and analysis. Only the material price of the concrete will be compared because the manufacturing process for the RFGC technologically is not available in the current time frame of development.

\subsection{Design of rectangular RC and RFGC beams}

Figure 3 shows two homogeneous $(p=0) \mathrm{RC}$ beams of $69 \mathrm{MPa}$ and $28 \mathrm{MPa}$ concrete compressive strengths, namely Case- 1 and Case-3, respectively. Case- 2 in Fig. 3 shows an RFGC beam cross-section of functionally graded concrete compressive strengths which vary from $28 \mathrm{MPa}$ at the bottom fiber and $69 \mathrm{MPa}$ at the top fiber of the beam crosssection.

In this study, the graded function in Eq. (1) of the concrete compressive strengths is selected to follow the degree of polynomial order of $p=1$ (linear), 2 (quadratic) and 3 (cubic) variation of cases. The selection of higher order degree of the polynomial in this study is because in practice, it is not easy to manufacture or by chance find a smooth linear gradation of FGC beam. Instead, the quadratic or cubic functions are more likely to be found in real concrete structures.

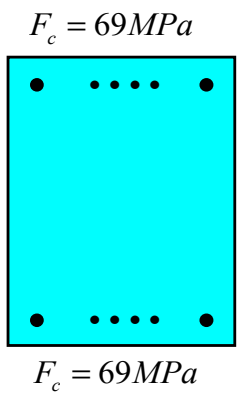

Case-1
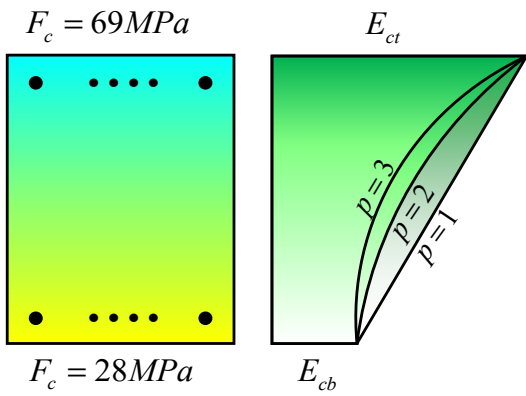

Case-2

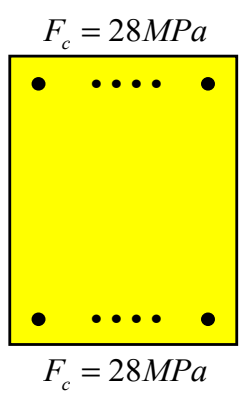

Case-3

Fig. 3. Cases for a comparison study of a rectangular RF/RFGC beams. 
The elastic moduli [12] can be evaluated from the compressive strength and weight density of the concrete as,

$$
\begin{array}{ll}
E_{c}=2.10 \times 10^{4} \times\left(\frac{\gamma_{c}}{23}\right)^{3 / 2} \times\left(\frac{F_{c}}{20}\right)^{1 / 2} & \left(F_{c} \leq 36 \mathrm{~N} / \mathrm{mm}^{2}\right) \\
E_{c}=3.35 \times 10^{4} \times\left(\frac{\gamma_{c}}{24}\right)^{2} \times\left(\frac{F_{c}}{60}\right)^{1 / 3} & \left(F_{c}>36 \mathrm{~N} / \mathrm{mm}^{2}\right)
\end{array}
$$

where, $E_{c}$ is the elastic modulus of concrete in $\mathrm{N} / \mathrm{mm}^{2} ; F_{c}$ is the compressive design strength of concrete in $\mathrm{N} / \mathrm{mm}^{2}$ and $\gamma_{c}$ is the weight density of concrete in $\mathrm{kN} / \mathrm{m}^{3}$. The weight densities [12] of $\gamma_{c}=23 \mathrm{kN} / \mathrm{m}^{3}$ and $\gamma_{c}=25 \mathrm{kN} / \mathrm{m}^{3}$ correspond to concrete with compressive strengths of $F_{c}=28 \mathrm{~N} / \mathrm{mm}^{2}$ and $F_{c}=69 \mathrm{~N} / \mathrm{mm}^{2}$, respectively. The weight density of $\gamma_{s}=78 \mathrm{kN} / \mathrm{m}^{3}$ is assigned to the steel bar.

\subsection{Volume fraction of FGC beam cross-section}

To calculate the price material of each case, the volume fraction of the respective material constituent in the FGC can be determined from the weight density distribution following Eq. (1).

The FGC weight density distribution can be expressed as:

$$
\gamma_{c}(y)=\gamma_{c b}\left[1+\frac{\gamma_{c t}-\gamma_{c b}}{\gamma_{c b}}\left(\frac{y}{h}\right)^{p}\right]
$$

where $\gamma_{c}(y)$ is the weight density of concrete at $y$ ordinate; $\gamma_{c b}$ is the weight density of concrete at the bottom of the beam cross-section; $\gamma_{c t}$ is the weight density of concrete at the top of the beam cross-section.

By integrating Eq. (16) along the depth of the FGC beam's cross-section, we can obtain the total volume per unit depth $V$ of the FGC from:

$$
V=\int_{0}^{h}\left\{\gamma_{c b}\left[1+\frac{\gamma_{c t}-\gamma_{c b}}{\gamma_{c b}}\left(\frac{y}{h}\right)^{p}\right] b(y)\right\} d y
$$

where $b(y)$ is the $y$-variable width of the FGC beam cross-section.

The volume of a fraction of a rectangular section, where the width $b(y)=b$ is a constant, of the FGC made of two concrete strength components, then can be determined by integrating Eq. (16) which results in:

$$
\begin{aligned}
& \text { for } p=0 \rightarrow V_{c t}=V_{c b}=V \\
& \text { for } p=1 \rightarrow V_{c t}+V_{c b}=2 V \\
& \text { for } p=2 \rightarrow V_{c t}+2 V_{c b}=3 V \\
& \text { for } p=3 \rightarrow V_{c t}+3 V_{c b}=4 V
\end{aligned}
$$

where $V_{c b}, V_{c t}$ and $V$ are the volumes of the corresponding compressive strength of concretes at the bottom fiber, top fiber and entire beam's cross-section, respectively. 


\subsection{Price of material calculation}

Table 1 shows the average unit price of homogeneous concrete material and steel bar available in the construction material price standard in Japan at present (2018).

Table 1. Concrete and steel bar prices (2018 average price market in Japan).

\begin{tabular}{|c|c|}
\hline $\begin{array}{c}\text { Strength } \\
\boldsymbol{F}_{\boldsymbol{c}} \text { (MPa) }\end{array}$ & $\mathbf{Y E N} / \mathbf{m}^{\mathbf{3}}$ \\
\hline 28 & 17400 \\
\hline 69 & 34700 \\
\hline
\end{tabular}

\begin{tabular}{|c|}
\hline Steel \\
SD-345 \\
(YEN/Ton) \\
\hline 67000 \\
\hline
\end{tabular}

As a base for comparison study, the high strength concrete of RC beam (Case-1) is designed to determine the appropriate bending moment for loading, its dimension of the cross-section and required reinforcing steel bars. The results are then used for designing the other cases to find the optimal beam cross-section dimensions and required reinforcing steel bars. The design is optimized by finding a suitable loading of bending moments that are close to Eqs. (13-14), the dimensions of the cross-section, and requirement of reinforcing steel bars within the allowable stress limit of concrete and steel bar materials. The allowable stress of concrete is determined from $\bar{\sigma}_{c}=F_{c} / 3$ and the allowable stress of steel bars is limited by $\bar{\sigma}_{s}=215 \mathrm{~N} / \mathrm{mm}^{2}$ (Steel Grades Carbon Steel SD345).

The results of the design and analysis of the RC and RFGC beam subjected to the bending moment are tabulated in Table 2 . The beam cross-section dimensions $(b \times h)$ and required steel bars and the total material prices are also shown in Table 2.

In each Case, the volume of the concrete is computed from the fraction volume given by Eq. (18) multiplied by the corresponding weight density and unit price shown in Table 1. The price of steel bars per unit length is calculated from the unit price shown in Table 1.

Table 2. Price comparison of RC and RFGC rectangular beams subjected to bending moment $\left(M_{\text {design }}=340 \mathrm{kN} . \mathrm{m}\right)$.

\begin{tabular}{|c|c|c|c|c|c|c|}
\hline \multirow[t]{2}{*}{ Case } & \multirow{2}{*}{$\begin{array}{c}b \times h \\
(\mathbf{m m} \times \mathbf{m m})\end{array}$} & \multicolumn{2}{|c|}{$\begin{array}{c}\text { Concrete volume } \\
\left(\mathrm{m}^{3}\right) \text { per unit } \\
\text { length }\end{array}$} & \multirow[t]{2}{*}{$p$} & \multirow{2}{*}{$\begin{array}{l}\text { Steel bars } \\
\text { (top) } \\
\text { (bottom) }\end{array}$} & \multirow{2}{*}{$\begin{array}{c}\text { Total price } \\
\text { per meter length } \\
\text { (Yen) }\end{array}$} \\
\hline & & $\begin{array}{c}F_{c}= \\
28 \mathrm{MPa}\end{array}$ & $\begin{array}{c}F_{c}= \\
69 \mathrm{MPa}\end{array}$ & & & \\
\hline 1 & $320 \times 600$ & 0.0000 & 0.1920 & 0 & $\begin{array}{l}2 \times 3 \times \phi 29 \\
2 \times 3 \times \phi 29\end{array}$ & $\begin{array}{c}10805 \\
(+25.7 \%)\end{array}$ \\
\hline $2 \mathrm{~A}$ & $300 \times 600$ & 0.0900 & 0.0900 & 1 & $\begin{array}{l}1 \times 2 \times \phi 29 \\
2 \times 3 \times \phi 29 \\
\end{array}$ & $\begin{array}{c}7451 \\
(-13.3 \%) \\
\end{array}$ \\
\hline $2 \mathrm{~B}$ & $300 \times 600$ & 0.1200 & 0.0600 & 2 & $\begin{array}{l}1 \times 2 \times \phi 29 \\
2 \times 3 \times \phi 29\end{array}$ & $\begin{array}{c}6932 \\
(-19.3 \%)\end{array}$ \\
\hline $2 \mathrm{C}$ & $300 \times 600$ & 0.1350 & 0.0450 & 3 & $\begin{array}{l}1 \times 2 \times \phi 29 \\
2 \times 3 \times \phi 29\end{array}$ & $\begin{array}{c}6672 \\
(-22.4 \%) \\
\end{array}$ \\
\hline 3 & $450 \times 770$ & 0.3465 & 0.0000 & 0 & $\begin{array}{l}1 \times 5 \times \phi 25 \\
1 \times 5 \times \phi 25\end{array}$ & 8594 \\
\hline
\end{tabular}

\section{Results and conclusion}

From Table 2, in general, Cases 2A-C are the RFGC beams with lower material prices compared to either the normal RC (Case-3) and high strength RC (Case-1). Apparently, the high strength RC (Case-1) has a higher material price compared to the normal RC (Case-3). 
In Fig. 4, the lowest material price is found at Case- $2 \mathrm{C}$ where the gradation function of compressive strength is following the $3^{\text {rd }}$ degree of polynomial.

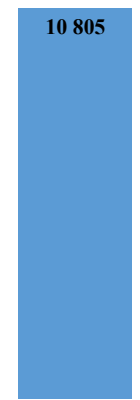

Case-1

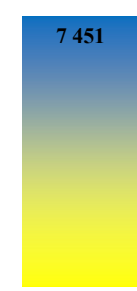

Case-2A

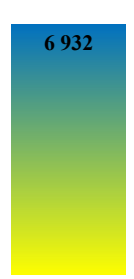

Case-2B

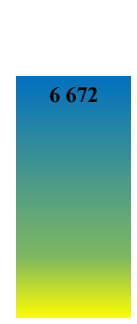

Case-2C

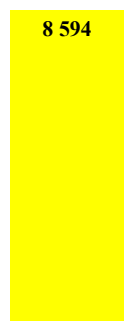

Case-3

Fig. 4. Price comparison of concrete material (Japanese Yen/meter length).

The following conclusions can be drawn from the present case study:

1. The $3^{\text {rd }}$ degree of polynomial assumption, which is most likely found in the built structural members of the graded concrete distribution, was found to be the most effective combination for FGC material. Therefore, there is no need to produce the linear $(p=1)$ FGC which is, indeed, more difficult to manufacture.

2. By using the RFGC (Case-2), the weight of the normal RC (Case-3) can be reduced by $41.8 \%$ less, and thereby, lightweight structure and more spaces can be gained in designing high-rise building.

3. Given the material price comparison, the RFGC beams are more economical than both the normal and high strength RC beams.

\section{References}

1. P. Stroeven, J. Hu, Cem. Concr. Compos. 29, 313-323, (2007)

2. A. Hidayat, P. Purwanto, J. Puspowardojo, F.A. Aziz, Procedia Eng. 125, 1023-1029, (2015)

3. M. Koizumi, Compos. Part B Eng. 28 (1-2), 1-4, (1997)

4. S. Amada, Y. Ichikawa, T. Munakata, Y. Nagase, H. Shimizu, Compos. Part B Eng. 28 (1-2), 13-20, (1997)

5. E.C.N. Silva, M.C. Walters, G.H. Paulino, J. Mat. Science 41 (21), 6991-7004, (2006)

6. K. Ghavami, C.S. Rodrigues, S. Paciornik, Asian J. Civil Eng. 4 (1), 1-10, (2015)

7. A.L. Han, B.S. Gan, S.A. Kristiawan, T.H. Trinh, CESB, 1092-1098, (2016)

8. B.S. Gan, A. Han, M.M.A. Pratama, Procedia Eng. 125, 885-891, (2015)

9. A.L. Han, B.S. Gan, M.M.A. Pratama, Int. J. Technol. 5, 732-740, (2016)

10. A.L. Han, B.S. Gan, M.M.A. Pratama, Int. J. Eng. Technol. Innov. 5 (4), 233-241, (2015)

11. M.M.A. Pratama, A.L. Han, B.S. Gan, B.S. Umniati, P. Risdanareni, S. Fauziyah, AIP Conf. Proc. 1887, (2017)

12. Architectural Institute of Japan, Standard for Structural Calculation of Reinforced Concrete Structures, AIJ, Japan, (2010) 